\title{
APPLICATION OF MODERN 3D IMAGE ACQUISITION SYSTEMS TO THE MORPHOLOGICAL ANALYSIS OF FACES: A NOVEL APPROACH FOR THE ASSESSMENT OF FACIAL GROWTH
}

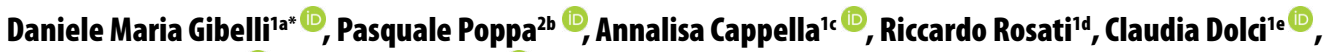 \\ Cristina Cattaneo $^{2 f}\left(\mathbb{0}\right.$, Chiarella Sforza ${ }^{1 g}$ (1) \\ 'Department of Biomedical Sciences for Health, Faculty of Medicine and Surgery, University of Milan, Milan, Italy \\ 2LABANOF, Laboratory of Anthropology and Forensic Odontology, Department of Biomedical Sciences for Health, Faculty of Medicine and Surgery, University \\ of Milan, Milan, Italy
}

aMD, PhD, Associate Professor; e-mail: daniele.gibelli@unimi.it; ORCIDiD: https://orcid.org/0000-0002-9591-1047

'BSC, PhD; pasquale.poppa@unimi.it; ORCIDiD: https://orcid.org/0000-0002-9288-5576

'BSC, MA, PhD; annalisa.cappella@unimi.it; ORCIDiD: https://orcid.org/0000-0002-4527-4203

dDDS, PhD; riccardo.rosati@outlook.com

eMD; claudia.dolci@unimi.it; ORCIDiD: https://orcid.org/0000-0002-3060-4097

fBSc, MD, MA, PhD; cristina.cattaneo@unimi.it; ORCIDiD: https://orcid.org/0000-0003-0086-029X

9MD, Professor, Head; chiarella.sforza@unimi.it; 0RCIDiD: https://orcid.org/0000-0001-6532-6464

\section{ABSTRACT}

d) https://doi.org/10.25241/stomaeduj.2020.7(4).art.5

Introduction The assessment of facial growth has always had a relevant importance in anatomy and morphological sciences. This article aims at presenting a method of facial superimposition between 3D models which provides a topographic map of those facial areas modified by growth.

Methodology Eight children aged between 6 and 10 years were recruited. In December 2010 they underwent a 3D scan by the Vivid 910 laser scanner (Konica Minolta, Osaka, Japan). The same procedures were performed another five times, in June 2011, September 2011, January 2012 and September 2012; in total 6 analyses were performed on the same subjects in a time span of 21 months.

Three-dimensional digital models belonging to the same individual were then superimposed on each other according to 11 facial landmarks. Three comparisons were performed for each individual, referring to the period between December 2010 and June 2011, between June 2011 and January 2012 and between January and September 2012.

Results Results show that the protocol of superimposition gives a reliable image of facial growth with high sensibility: in detail, even the slight facial modifications due to different expressions are recorded. The method can also quantify the point-to-point difference between the two models, and therefore give an indication concerning the general increase or decrease of facial volume.

Conclusion This approach may provide useful indications for the analysis of facial growth on a large sample and give a new point of view of the complex field of face development.

\section{KEYWORDS}

Anatomy; Morphological Sciences; Facial Assessment; Facial Growth; Laser Scanner.

\section{INTRODUCTION}

Facial assessment, performed both from a metrical and morphological point of view, is one of the most ancient issues in anatomical and anthropological sciences, since the face is the main tool for communication and interaction with the environment; pionieristic studies were performed by Leonardo da Vinci and Albrecht Dürer, and deal with the graphical methods useful to describe the

(c) (1) ) () OPEN ACCESS This is an Open Access article under the CC BY-NC 4.0 license. Peer-Reviewed Article

Citation: Gibelli DM, Poppa P, Cappella A, Rosati R, Dolci C, Cattaneo C, Sforza C, Application of modern 3d image acquisition systems to the morphological analysis of faces: a novel approach for the assessment of facial growth. Stoma Edu J. 2020;7(4):268-273

Received: October 12, 2020 Revised: October 23, 2020; Accepted: October 25, 2020; Published: October 27, 2020

*Corresponding author: Prof. Daniele Maria Gibelli, Dipartimento di Scienze Biomediche per la Salute, Facoltà di Medicina e Chirurgia, Università

degli Studi di Milano, V. Mangiagalli 31, Milan, Italy

Tel: +39-02-50315339; Fax: +39-02-50315724; e-mail: daniele.gibelli@unimi.it

Copyright: $\odot 2020$ the Editorial Council for the Stomatology Edu Journal. 


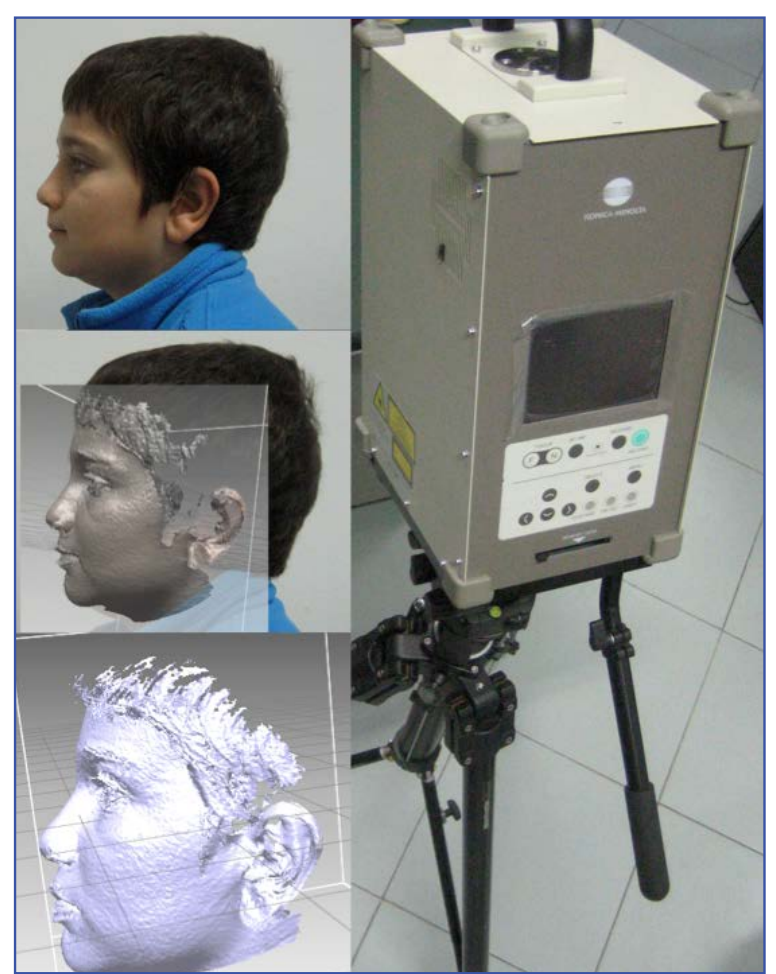

Figure 1. on the right, 3D laser scanner (Konica Minolta, Vivid 910); on the left, example of acquisition of the face of a child recruited in the study.

facial morphological variation [1]. Charles Darwin first analysed the facial expressions and explored the importance of the face in evolutionary programs of interaction between individuals of the same species [2]. In the $19^{\text {th }}$ century, with the beginning of modern forensic anthropology, the metrical analysis of the face was analysed with identification purposes by Alphonse Bertillon who developed a system of recording called bertillonage [3]; in the early $20^{\text {th }}$ century, the importance of the face was explored for what concerns the relation between personality, moral behaviour and morphological facial traits, by Lombroso [4]. The revolutionary discovery of $X$-rays allowed scientists to perform more precise analyses of facial morphology, which was one of the main issues of the new technology [5]: however, only in the last 30 years the study of the face has gained popularity as shown by the huge increase of studies published on this topic thanks also to the introduction of more advanced diagnostic technologies such as CT scan and MRI (magnetic resonance imaging). Since the early eighties, both ot them have been widely applied to the 3D study of cranium and facial soft tissues [6]. Also, modern 3D image acquisition systems, both based on a non-contact (laser scanner, stereophotogrammetry) and contact approach (electromagnetic and electromechanical digitizers, ultrasound probes) have been introduced for anthropological, anatomical and clinical investigations [7]. The use of such technologies allowed the operators to perform an easier recording and quantification of facial metrical parameters, in order to increase data and to analyse the chances of practical application of the information obtained. As to the relation between craniometric measurements and age, literature provides several articles dealing with the development of different facial traits in children and juveniles; Farkas for example analysed the degree of growth of different cranial and facial parameters, pointing out the percentual modifications [8]. In more recent times, different studies have been published concerning the sectorial development of single facial areas, such as lips [9], ears [10,11], nose [12] and the orbital region $[13,14]$. The modification of face with age was improved by analyses concerning the movement of facial landmarks with time, with consequent modifications of facial profiles $[15,16]$; in detail, literature ascertained that between 6 and 11 years of age the vertical diameters of the face increase, especially in the middle and upper thirds of faces: then, at 10 years circa in females and at 13 years circa in males the facial profiles are close to the adult model, with a dislocation of the main landmarks. Up to 11 years the trend is similar in both genders; then females show a spurt at 11-12 years circa, followed by a progressive decrease of bodily development. On the other hand males are affected by a delayed growth, which remains constant from 11-12 to 1617 years. As a consequence, at 14-15 years of age females have a facial configuration similar to the adult one, whereas males of the same age are still in active growth. In females, the upper and lower thirds have their higher degree of development up to 11-12 years circa; on the other side, males begin to increase the lower third from 12 to 13 years.

As one can notice, most of the literature actually deals with linear measurements which remain the traditional way to explore facial morphology: in such cases, the increase of single parameters is usually assessed as a percentage of the adult measurements. In time, the linear approach to facial growth has provided epidemiological information concerning the modification of different parameters; in the last years, research in this field has known a relevant improvement thanks to the advanced 3D image acquisition techniques: the main advantage consists in the chance of measuring dimensional parameters which cannot be evaluated in vivo (for example, geometrical areas and volumes included within facial landmarks). This was an attempt both at applying the 3D image acquisition systems and at finding the same standardization as for linear measurements $[12,13]$. However the measurement of facial surfaces and volumes is only one of the advantages deriving from the application of modern technologies: in fact these methods allow the operators to acquire a 3D digital model of face, which can be used in a virtual space and, for example, superimposed to other images. The main task consists in performing a pointto-point comparison between the two surfaces. An example of such application derives from the study of facial motion and mimicry, provided by Popat et al. who used a stereophotogrammetric motion 


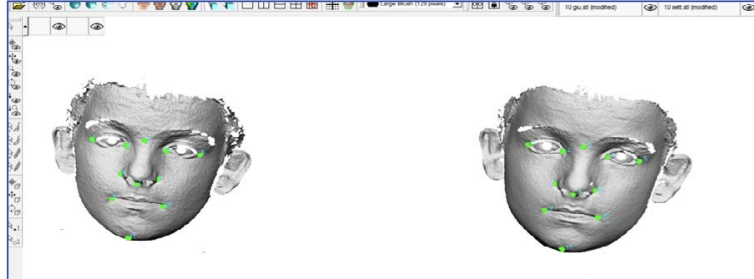

Figure 2. definition of 11 landmarks for facial superimposition.
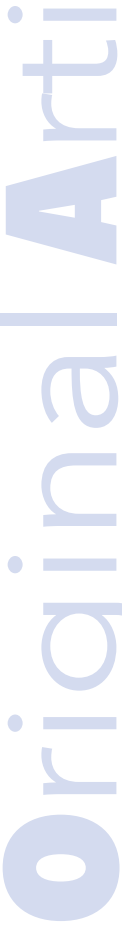
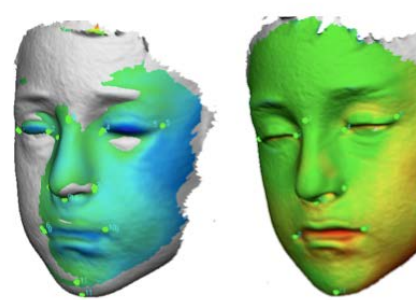

Figure 4. chromatic figures of growth in child $n^{\circ} 1$.

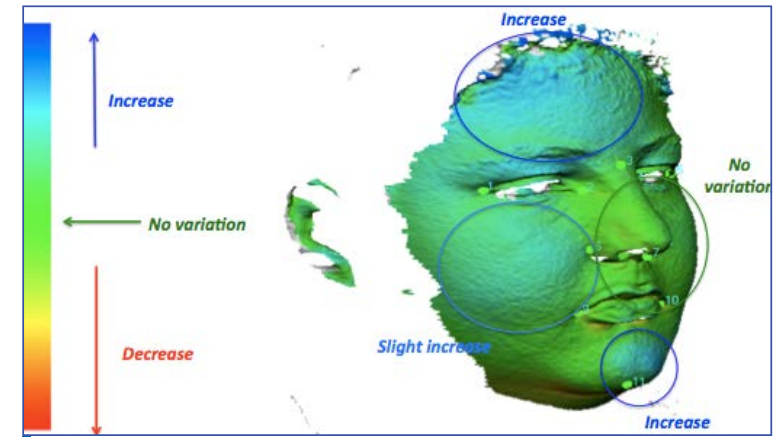

Figure 3. example of chromatic sheet of comparison between two 3D models from the same individual.

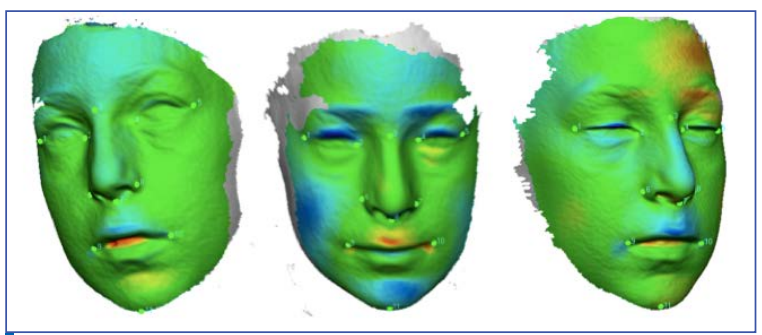

Figure 5. chromatic figures of growth in child $n^{\circ} 2$.

and left $3 / 4$ position (Fig.1). The same procedures were performed another five times, in June 2011, September 2011, January 2012 and September 2012; in total 6 analyses were performed on the same subjects in a time span of 21 months.

The modification of facial morphology on 3D scans was evaluated from a qualitative point of view following a protocol of facial comparison. In detail, 11 facial landmarks (right and left endocanthion, exocanthion, alare, chelion: in the midline selion, gnathion, subnasale) were identified on all the 3D scans from the same individual by VAM (Canfield Scientific, NJ, USA) software. The system was required to superimpose two $3 \mathrm{D}$ models from the same subject in order to reduce the distance between the corresponding points (Fig. 2). In order to follow facial growth, three comparisons were performed for each individual, referring to the period between December 2010 and June 2011, between June 2011 and January 2012 and between January and September 2012. This procedure allowed the operator to obtain a chromatic sheet of the face, where the growing zones are colored in blue and the zones which showed a reduction are in red.The unchanged areas are indicated in green (Fig. 3).

\section{RESULTS}

Eight children, aged between 6 and 10 years, four males $\left(n^{\circ} 1,2,5,7\right)$ and four females $\left(n^{\circ} 3,4,6,8\right)$ were recruited: subjects affected by facial pathologies and deformities were excluded. All the following analyses were performed after signature of a specific consent by the parents. In December 2010 the eight children underwent a 3D scan by Vivid 910 laser scanner (Konica Minolta, Osaka, Japan); a 3D digital model was built by five scans obtained in five positions (frontal view, right and left profile, right
Subject $n^{\circ} 1$ (male, analysed between 80 and 101 months of age) showed an increase in the lower third of the face between December 2010 and June 2011: limited areas of increase are observed also in the palpebral regions, although they may be due to the different position of the eyelids during the second scanning (the child had his eyes closed during the second scan, whereas they were open 


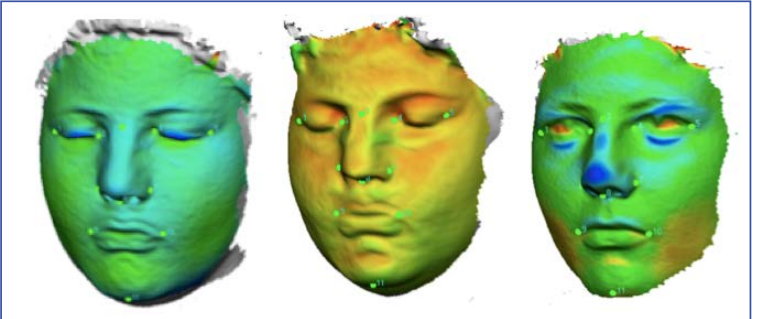

Figure 6. chromatic figures of growth in child $n^{\circ} 5$.

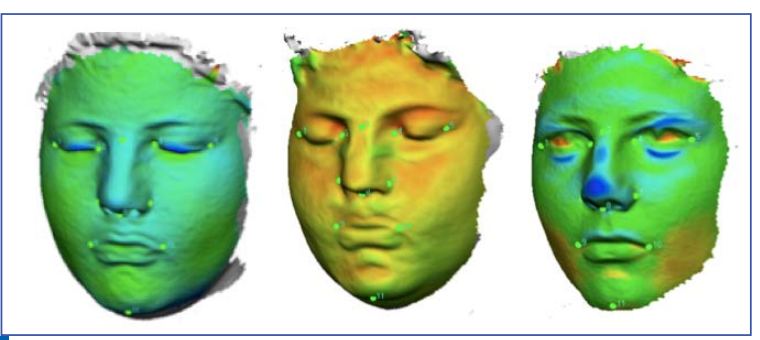

Figure 8. chromatic figures of growth in child $n^{\circ} 3$.

during the first one). In January 2012 there was an increase of the entire face, but only on the left side in the perioral region and nose, whereas the right side did not show modifications. At the end of the data collection, the same region was affected by a slight decrease (Fig. 4).

Child $\mathrm{n}^{\circ} 2$ (male, analysed between 123 and 144 months of age) first showed an increase in the frontal area, and at the second comparison an increase in the malar region, bilaterally. However, also in this case, the increase may be due to the smiling expression of the child. At the end of the experiment, the areas with a true increase were the nose and the perioral region (Fig. 5). Subject $n^{\circ} 5$ (male, analysed between 131 and 152 months of age) showed an increase at first limited to the left side of the face, whereas in the second comparison the entire face was affected by a decrease in size. In the last time point assessment, the nose and the right and left malar zones showed an increase in size (Fig. 6).

Subject $n^{\circ} 7$ (male, analysed between 102 and 123 months of age) showed an increase at the nose, bilateral malar zones and perioral region. However, since the second comparison, the entire face was affected by a strong decrease, first limited to the left side of the face, and then extended to the right side (Fig. 7). On the other hand, the girls analysed showed different modifications: subject $n^{\circ} 3$ (analysed between 86 and 107 months of age) in all the comparisons showed an increase of the oral region, with limited modifications (slightly prone to the decrease) in the rest of the face (Fig. 8).

However, also in case of the females, strong differences between age ranges within the same individual were noticed; subject $\mathrm{n}^{\circ} 4$ (analysed between 108 and 129 months of age) both during the first and second comparison was affected by a decrease of facial areas, followed by an increase of the entire facial zone in the last time point (Fig. 9).

The same differences, although with a stronger trend

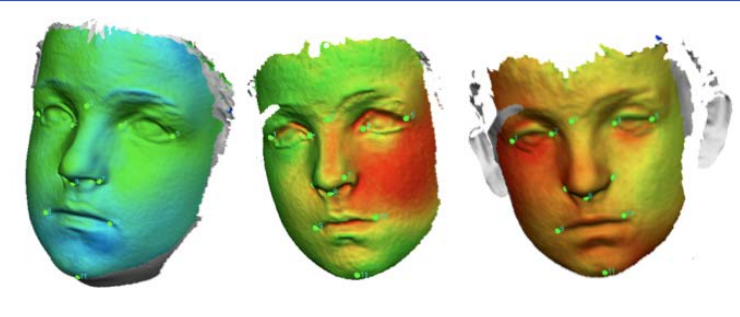

Figure 7. chromatic figures of growth in child $n^{\circ} 7$.

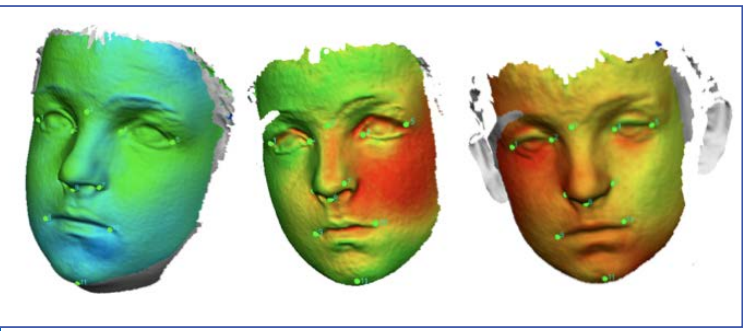

Figure 9. chromatic figures of growth in child $n^{\circ} 4$.

towards increments in facial dimensions, are shown by the three comparisons of subject $n^{\circ} 6$ (analysed between 119 and 140 months of age) (Fig. 10).

Subject $n^{\circ} 8$ (analysed between 72 and 93 months of age) showed an increase at the left malar zone; at the second and third comparison, an increase was observed at the cheek: however, also in this case, the different expression of the child may have played a role (Fig. 11).

\section{DISCUSSION}

The study of facial growth has always been one of the most interesting and frequently treated topics in anatomy and morphology, so far conducted through the assessment of linear measurements, as stated in Farkas' study [8]. The introduction of modern 3D technologies gave a relevant impulse to the analysis of deeper dynamics of facial development by the metrical assessment of surfaces and volumes $[20,21]$. However, additional information may be available by the superimposition of 3D models from the same individual, which may provide a topographic pointto-point visualization of growth processes.

The study aimed at verifying the relation of a novel protocol for the superimposition of 3D models, as a study model for the assessment of facial growth: the preliminary results showed interesting starting points for further research.

First, the analysis of facial surfaces pointed out that the increase of surfaces does not show a progressive trend in time; this indicates that the modification of facial surfaces is affected by other variables in specific periods, such as environmental and individual factors.

Another interesting information deriving from the analysis of facial surfaces in vivo is the general lack of symmetry in growth for both males and females. This is an interesting datum, since it confirms the general information concerning the asymmetry of 


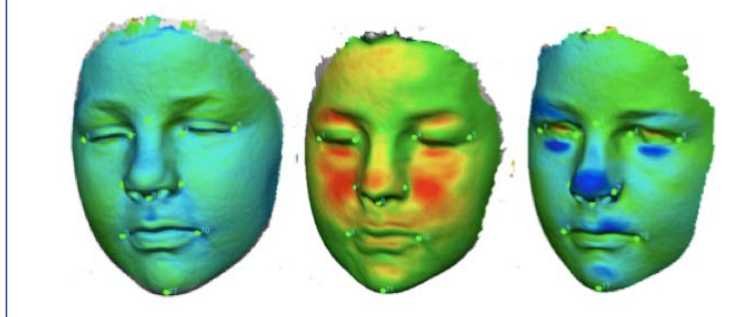

Figure 10. chromatic figures of growth in child $n^{\circ} 6$.

facial measurements [19,22]. The asymmetry of the face is well known, and is observed both in adults and children: the actual study points out that facial growth also seems to follow the same asymmetry. Finally, the method of superimposition was able to detect the slight modifications due to the different facial expressions: this provides an additional indication concerning the sensitivity of the approach.

\section{CONCLUSION}

From this point of view, the actual study points out that the superimposition of 3D models may provide additional information, especially with respect to the sectorial development of facial areas. The application of this technique to few children provided some insight into a deeper analysis of the phenomenon of facial growth: clearly further studies are needed, on larger samples, in order to test the new protocol and provide a more decisive contribution to the analysis of facial age-related modifications. Nonetheless, in

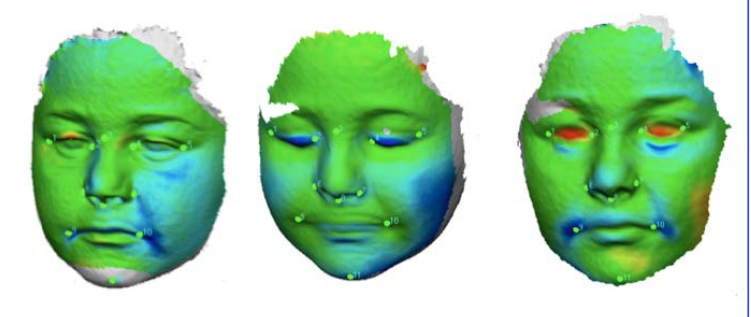

Figure 11. chromatic figures of growth in child $n^{\circ} 8$.

general, the present technical note has shown the large potential of the applied method in the study of facial morphology.

\section{CONFLICT OF INTEREST}

None.

\section{AUTHOR CONTRIBUTIONS}

DG: concept, protocol, data gathering, data analysis, data interpretation, revision of the manuscript, PP: protocol, data gathering, data analysis, AC: data gathering, data analysis, data interpretation, RR: data gathering, data analysis, data interpretation, CD: data gathering, data analysis, data interpretation, CC: concept, data interpretation, revision of the manuscript, CS: concept, data interpretation, revision of the manuscript.

\section{ACKNOWLEDGMENTS}

None.

\section{REFERENCES}

1. Peck S, Peck L. Selected aspects of the art and science of facial esthetics. Semin Orthod. 1995; 1(2):105-126. doi: 10.1016/s10738746(95)80097-2.

CrossRef PubMed Google Scholar Scopus

2. Darwin C. The expression of emotions in man and animals. London, UK: John Murray, Albemarle Street; 1872.

Google Scholar

3. Bertillon A. Signaletic instructions including the theory and practice of anthropometrical identification. Chicago, IL: The Werner Company; 1896.

CrossRef Google Scholar

4. Lombroso C. [The delinquent man]. Milano, IT: Hoepli; 1876.

5. Broadbent BH Sr, Broadbent BH Jr, Golden WH. Bolton

standards of dentofacial developmental growth. Saint Louis, MO:

CV Mosby Co; 1975. doi:10.1097/00006534-197701000-00023.

CrossRef Google Scholar

6. Adams GL, Gansky SA, Miller AJ, et al. Comparison between traditional 2-dimensional cephalometry and a 3-dimensional approach on human dry skulls. Am J Orthod Dentofacial Orthop. 2004;126(4):397-409. doi: 10.1016/j.ajodo.2004.03.023.

Full text links CrossRef PubMed Google Scholar Scopus WoS

7. Gibelli D, Dolci C, Cappella A, Sforza C. Reliability of optical devices for three-dimensional facial anatomy description: a sistematic review and meta-analysis. Int J Oral Maxillofac Surg. 2020;49(8):1092-1106. doi: 10.1016/j.ijom.2019.10.019.

Full text links CrossRef PubMed Google Scholar

8. Farkas LG. Anthropometry of the head and face. 2nd ed. New York, NY: Raven Press; 1994.

9. Ferrario VF, Sforza C, Schmitz JH, et al. Normal growth and development of the lips: a 3-dimensional study from 6 years to adulthood using a geometric model. J Anat. 2000;196 (Pt 3) (Pt 3):415-23. doi: 10.1046/j.1469-7580.2000.19630415.x. PMID: 10853963; PMCID: PMC1468077.

Full text links CrossRef PubMed Google Scholar Scopus WoS
10. Ferrario VF, Sforza C, Ciusa V, et al. Morphmetry of the normal human ear: a cross-sectional study from adolescence to midadulthood. J Craniofac Genet Dev Biol. 1999;19(4):226-233. PMID: 10731092.

PubMed Google Scholar

11. Sforza C, Grandi G, Binelli M, et al. Age- and sex-related changes in the normal human ear. Forensic Sci Int. 2009;187(13):110.e1-7. doi: 10.1016/j.forsciint.2009.02.019.

Full text links CrossRef PubMed Google Scholar Scopus WoS 12. Sforza C, Grandi G, De Menezes M, et al. Age- and sex-related changes in the normal human external nose. Forensic Sci Int 2011;204(1-3):205.e1-9. doi: 10.1016/j.forsciint.2010.07.027. Full text links CrossRef PubMed Google Scholar Scopus WoS 13. Sforza C, Grandi G, Catti F, et al. Age- and sex-related changes in the soft tissues of the orbital region. Forensic Sci Int 2009;185(1-3):115.e1-8. doi: 10.1016/j.forsciint.2008.12.010. Full text links CrossRef PubMed Google Scholar Scopus WoS 14. Ferrario VF, Sforza C, Colombo A, et al. Morphometry of the orbital region: a soft-tissue study from adolescence to midadulthood. Plast Reconstr Surg. 2001;108(2):285-292; discussion 293. doi: 10.1097/00006534-200108000-00001.

Full text links CrossRef PubMed Google Scholar Scopus WoS 15. Ferrario VF, Sforza C, Serrao G, et al. Growth and aging of facial soft tissues: a computerized three-dimensional mesh diagram analysis. Clin Anat. 2003;16(5):420-433. doi: 10.1002/ca.10154. CrossRef PubMed Google Scholar Scopus WoS

16. Ferrario VF, Sforza C, Poggio CE, et al. Facial volume changes during normal human growth and development Anat Rec. 1998;250(4):480-487. doi: 10.1002/(SICI)10970185(199804)250:4<480::AID-AR12>3.0.CO;2-K.

Full text links CrossRef PubMed Google Scholar WoS

17. Popat H, Richmond S, Playle R, et al. Three-dimensional motion analysis - an exploratory study. Part 1: assessment of facial movement. Orthod Craniofac Res. 2008;11(4):216-223. doi: 10.1111/j.1601-6343.2008.00433.x.

Full text links CrossRef PubMed Google Scholar Scopus WoS 
18. Popat H, Richmond S, Playle R, et al. Three-dimensional motion analysis - an exploratory study. Part 2: reproducibility of facial movement. Orthod Craniofac Res. 2008;1 1(4):224-228. doi: 10.1111/j.1601-6343.2008.00435.x.

Full text links CrossRef PubMed Google Scholar Scopus WoS 19. Ferrario VF, Sforza C, Poggio CE, et al. Distance from symmetry: a three-dimensional evaluation of facial asymmetry. $J$ Oral Maxillofac Surg. 1994;52(11):1126-1132. doi: 10.1016/02782391(94)90528-2.

Full text links CrossRef PubMed Google Scholar Scopus WoS 20. Gibelli D, Pucciarelli V, Cappella A, et al. Are portable stereophotogrammetric devices reliable in facial imaging? A validation study of VECTRA H1 device. J Oral Maxillofac Surg.
2018;76(8):1772-1784. doi: 10.1016/j.joms.2018.01.021.

Full text links CrossRef PubMed Google Scholar

21. Gibelli D, Pucciarelli V, Poppa P, et al. Three-dimensional facial anatomy evaluation: reliability of laser scanner consecutive scans procedure $\mathrm{n}$ comparison with stereophotogrammetry Craniomaxillofac Surg. 2018;46(10):1807-1813. doi: 10.1016/j. jcms.2018.07.008.

CrossRef Google Scholar

22. Ferrario VF, Sforza C, Miani A Jr, et al. A three-dimensional

evaluation of human facial asymmetry. J Anat. 1995;186 ( Pt 1)(Pt

1):103-110. PMID: 7649806; PMCID: PMC1167276.

Full text links PubMed Google Scholar Scopus

\title{
Daniele Maria GIBELLI \\ MD, PhD, Associate Professor \\ Department of Biomedical Sciences for Health \\ Faculty of Medicine and Surgery \\ University of Milan \\ Milan, Italy

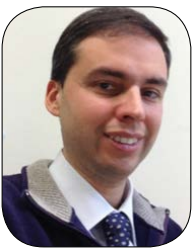

Dr. Gibelli is a physician specialized in Legal Medicine with a PhD in Morphological Sciences, and an associate professor in Human Anatomy.

His areas of expertise include 3D surface acquisition (laser scanner and stereophotogrammetry) and 3D image elaboration for documentation and analysis of faces and osteological and dental material, 3D segmentation from CT-scan and NMR, the validation of novel techniques for 3D acquisition and assessment of their reliability in the analysis of facial anatomy. The specific topics include the study of facial morphology in acquired and genetic pathologies, of facial mimicry in healthy subjects and patients affected by facial nerve palsy, the analysis of anatomical variants of the cranium, the assessment of skeletal morphology. He authored more than 120 articles published in peer-reviewed impacted journals.

\section{Ougstions}

\section{Which technique of acquisition is not $\mathrm{X}$-ray based?}

\author{
口a. Laser scanner; \\ ab. CT-scan; \\ ac. Conventional radiography; \\ ad. CBCT scan.
}

\section{Who analysed facial growth in children setting percentual modifications?}

口a. Leonardo da Vinci;

ab. Charles Darwin;

口c. Leslie Farkas;

ad. Alphonse Bertillon.

\section{Through which methods can facial morphology be analysed?}

Da. Laser scanner;

ab. CT-scan;

ac. NMR;

ad. All the above.

\section{Which facial measurements most increase between 6 and 11 years?}
a. Horizontal ones;
b. Vertical ones;
ac. Both of them;
ad. None. 